Cover Sheet for a Hanford

Historical Document

Released for Public Availability

Released 1994

Prepared for the U.S. Department of Fnergy under Contract DE-AC06-76RLO 1830

Pacific Northwest Laboratory

Operated for the U.S. Department of Energy

by Battelle Memorial Institute

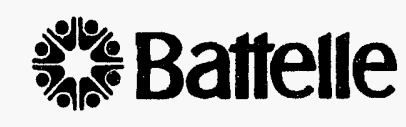

$$
\begin{gathered}
\text { RFREIVED } \\
\text { APR } 181994 \\
\therefore 11
\end{gathered}
$$

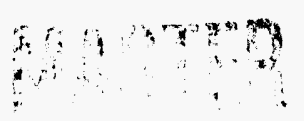




\section{DISCLAIMER}

This is a historical document that is being released for public availability. This was made from the best available copy. Neither the United States Government nor any agency thereof, nor Battelle Memorial Institute, nor any of their employees, makes any warranty, express or implied, or asoumes any legal liability or responsibility for the accuracy, completeness, or usefulness of any information, apparatus, product, or prociess disclosed, or represents that its use would not infringe privately owned rights. The views and opinions of authors expressed herein do not necessarily state or reflect those of the United States Government or any agency thereof. 


\section{PNL-9431}

Preface

Until recently, the attached report existed only as a draft account of the responses received concerning a questionnaire which had been sent to DOE/DOE Contractor facilities. This report has been published as a response to a congressional inquiry.

The following items should be noted by the reader:

* The questionnaire was sent to the DOE/DOE contractor facilities either late CY-1983 or early CY-1984. The draft report was submitted to program management at PNI on october 1 , 1984.

* All responses to the questionnaire have been destroyed. The facility numbers discussed in the report were assigned to the . responses in the order in which the responses were received. It is not possible to link a specific DOE/DOE contractor facility to a particular response.

* This report is a copy of the only copy found to date; a draft document which was submitted for comments. The author does not recall having incorporated any changes to the first, and only, draft.

* Although correspondence has been found which suggests that the report was sent to DOE/HQ, a transmittal letter has not been found.

R.J. Traub, Ph.D. March 15,1994 


\title{
RADIATION RECORDKEEPING PRACTICES AT DOE FACILITIES
}

\author{
R. J. Traub
}

In order to evaluate the radiation recordkeeping practices at DOE facilities, a questionnaire was sent to DOE and DOE contractor facilities which requested information concerning the recordkeeping systems. The questionnaire was sent to the DOE/DOE contractor facilities via DOE/HQ and the respective field offices. The questionnaire stipulated that at multiple contractor sites, only those facilities who kept the records should respond to the questionnaire; however, those responding should indicate the facilities for which they maintained records. Responses were received from 36 facilities (listed in Table 1); these responses account for 54 facilities

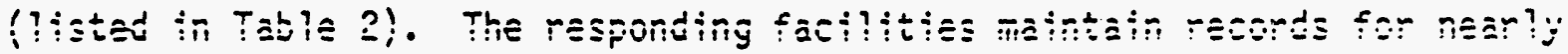
150,000 workers; these workers accounted for approximately 90 percent of the external radiation dose received in 1982 by DOE/DOE contractor employees (1982 Annual Report). These facilities also maintain records for a total of nearly 964,000 current and terminated employees.

- This report will follow the sequence of the questionnaire.

\section{LIFE TIME EXPOSURE - EXTERNAL RADIATION}

Twenty-four of the responding facilities were stated to have external dosimetry records on all employees; however, four of the respondents qualified their positive answer in such a way that would imply that records are not kept for all employees. The responses indicate that external radiation doses: would be available for the majority of "radiation workers" or "those with significant exposure potential." The difference between all workers and radiation workers is that at many facilities individuals, such as clerical workers, who would not enter the areas in which radiation or radioactive materials were expected, were not monitored for exposure to radiation or for deposition of radioactive material. Four facilities indicate that the records may be incomplete; one facility (\#7) reports that two of the previous contractors have exposure data; one facility (\#6) did not monitor employees prior to 1955 , a third facility (\#24) reports that no 
Allied Bendix Aerospace - Kansas City Division

Argonne National Laboratory - East

Battelle Columbus Laboratory/West Jefferson North Site

Brookhaven National Laboratory

DOE - Ames Laboratory

DOE - New Brunswick Laboratory

Environmental Measurements Laboratory

Feed Materials Production Center

Fermi National Accelerator Laboratory

Idaho National Engineering Laboratory

Inhalation Toxicology Research Institute

Laboratory for Energy-Related Health Research, U.C. Davis

Laboratory of Radiobiology and Environmental Health, U.C. S.F

Lawrence Livermore National Laboratory

Los Alamos National Laboratory - University of California

Mound Monsato Research Corporation

Nevada Test Site - Lawrence Livermore National Laboratory

Nevada Test Site - Reynolds Electrical and Engineering Co, Inc.

Oak Ridge Associated Universities

Oak Ridge Gaseous Diffusion Plant

Pacific Northwest Laboratory

Paducah Gaseous Diffusion Plant

Pantex

Pirellas Plant - General Electric Company

Portsmouth Site - Goodyear Atomic Corporation

Princeton Plasma Physics Laboratory

RMI Company - Extrusion Plant

Rockwell International Energy Systems Group

Rock Flats - Rockwell Space Division

Sandia National Laboratories - Albuquerque

Sandia National Laboratories - Livermore

Savannah River Plant

Stanford Linear Accelerator Center

U.C. Lawrence Berkeley Laboratory

UCLA - Warren Hall and Biomedical Cyciotron

Y-12 Plant 
Allied Bendix Aerospace - Kansas City Division Argonne National Laboratory - East

Battelle Columbus Laboratory - West Jefferson North Site Boeing Computer Services - Richland

Brookhaven National Laboratory

DOE - Ames Laboratory

DOE - Los Alamos Area Office

DOE-RL

DOE - New Brunswick Laboratory

DOE-SF Office

EG\&G - Nevada

Environmentai Measurements Laboratory

Feed Materials Production Center

Fermi National Accelerator Laboratory

General Electric - Hanford

Grand Junction Area Office

Hanford Environmental Health Foundation

Idaho National Engineering Laboratory

Inhålation Toxicology Research Institute

J. A. Jones Construction Services Company

Kaiser Engineers - Hanford; Bruam; and Vitro

Laboratory for Energy-Related Health Research

Laboratory of Radiobiology. and Environmental Health

Lawrence Livermore National Laboratory

Los Alamos National Laboratory

Mason and Hanger - Los Alamos Security Force

Mound Monsato Research Corporation

Nevada Test Site

North Las Vegas Facilities

Nuclear Rocket Development Station - Nevada

Oak Ridge Associated University

Oak Ridge Gaseous Diffusion Plant

Pacific Northwest Laboratory

Paducah Gaseous Diffusion Plant 
TABLE 2. Facilities for Whom a Response was Given (contd)

Pantex

Pinellas Plant - General Electric Company

Portsmouth Site

Princeton Plasma Physics Laboratory

RMI Company - Extrusion Plant

Rockwell Hanford Operation

Rockwell International - Energy Systems Group

Rocky Flats Plant - Rockwell Space Division

Sandia National Laboratories - Albuquerque

Sandia National Laboratories - Livermore

Savannah River Laboratory

Savannah River Plant

Stanford Linear Accelerator Center

UCLA - Warren Hall and Biomedical Cyclotron

U.C. Lawrence Berkeley Laboratory

UNC Nuclear Industries, Inc.

Westinghouse Hanford Company

West Valley - New York Project

$Y-12$ piant 
records have been found for the period 1949-1953, and the last facility (\#20) reports that it may be difficult to locate records for exposures which occurred prior to the formation of the operational health physics group.

The estimated costs to obtain the lifetime external radiation dose varied tremendously. In the case of current workers, the costs ranged from "minimal" (\#12, 2000 current employees) to approximately $\$ 5,500,000$ of computer time plus 44,000 man-hours of labor for one large facility ( $\$ 30$, 5500 current workers). The total costs, as estimated by the respondents was 47,621 man-hour plus $\$ 5,506,050$. The estimated period of time necessary to obtain lifetime doses for all currently employed radiation workers ranged from one (1) day to 2 years with one facility requiring approximateiy $2 a$ man-years oi eifort; this iast facijity dis not estimata tie time required to obtain the requested information.

In order to obtain lifetime external doses for all $\mathrm{Employees,} \mathrm{both}$ current and terminated, the cost estimates received from the facilities ranged from 8 man-hour (facility \#4, 14,000 total employees) or $\$ 250$ (facility \#3, 25,000 total employees) to 1,000,000 man-hours plus $\$ 40,000,000$ (facility $\# 30,40,000$ total employees). The very large range of estimated costs can, probably in large extent, be attributed to the difference between a computer based recordkeeping system and a "manual system". For example, facility \#7 estimates a total cost to obtain cumulative doses as \$2k labor and \$2k computer time; the total number of current and terminated workers is 82,000 . All records for facility \#? appear to be maintained in computer files. In contrast, facility \#30 estimates a total cost to obtain cumulative external doses for current and terminated employees to be approximately $1 \mathrm{M}$ man-hours plus $\$ 40 \mathrm{M}$; the total number of current and terminated workers is about 40,000. The records system for facility \#30 was described thusly "current year records are computer based and include cumulative totals for current employees. Previous years records are kept on microfilin."

The total estimated costs to obtain the cumulative external radiation dose of all workers, current and terminated, are 1,035,474 man-hours plus $\$ 40,014,450$. The period of time required to compile this data, without 
additional staffing, ranged from 1 week to 3.5 years. One facility (\#8, 55,000 total employees) stated that without extra staffing such information would be "almost impossible" to compile while another facility ( $\$ 31,2,000$ total employees) stated it would 'never' be able to perform the task with current staffing. Facility \#30 did not estimate a time to complete the task.

\section{LIFETIME DOSES - INTERNAL DOSIMETRY}

The second major section asked whether sufficient data existed to estimate cumulative lifetime doses from internally deposited radionuclides. As for the external doses, internal dose data is available only for those individuals whose working conditions may have a potential for an internal Exposure. Twenty-thres feci? ities report that sufficient information exists to report the cumulative internal doses for "radiation" or "monitored" workers. The data are not all the same at all facilities. At some facilities radiation doses may have been computed and recorded. Comments written on the returned questionnaire indicate that: at one facility (\#7) internal doses are recorded for significant intakes only; at another facility (\#6) workers were not monitored before 1955; the recorded data at three facilities (\#16, 17, 24) was stated to be inadequate for the estimations of internal doses. Other comments indicate that many facilities did not estimate an internal radiation dose uniess it appeared to be significant. In some cases, the internal dosimetry data appears to be in the form of quantity in the lung for in vivo and quantity of radionuclide per unit volume of urine for in vitro. Only 10 of the 36 facilities indicate that a calculated internal dose is recorded.

Considering the data recorded: at three facilities the integrated air concentrations of radioactive material are recorded; 23 record bioassay results; however, in Section $D$, seven of those who do not record bioassay results do record radionuclide excretion data. Nineteen facilities record the whole body counts, six record the estimated deposition based on mathematical models, 10 record a calculated internal dose, although 13 record an annual dose to the critical organ (from Section 0 ). The facilities that reported "other" indicated that they record annual bioassay various (unspecified) reports and incident files, and annual dose equivalent and 50 year dose equivalent. 
The questionnaire also requested an estimate of the costs which may be incurred to obtain cumulative internal doses for current and terminated workers. Two facilities estimated the cost in terms of cost per individual estimate. In these cases, the total cost estimate is taken as the product of the estimate for one individual and the total number of individuals for whom records exist. The cost estimate, for current workers, ranged from two man-hours (\#13, 900 current workers) to 44,000 man-hours of staff time (\#30, 5500 current workers). The total estimated costs to provide are 492,195 man-hours plus $\$ 5,700,800$.

In order to estimate the cumulative internal doses to all workers, current and terminated, the total cost estimates were 3,616,150 man-hours plus $\$ 40,200,800$.

Six facilities did not estimate the costs associated with estimating annual internal doses for either current or all workers. The estimate from these facilities stated only that such a project would be a major effort and would require staff labor to compute dose equivalent from raw data. These facilities account for 8046 current employees and approximately 27, ?.00 total employees.

It is difficult to know to what extent these.cost estimates are high or low. Two large facilities $(\# 1,30)$ estimated the cost per individual. The costs listed above are high to the extent that the same level of effort is not required for every individual.

The time required to have these estimates in hand ranged from one week to several years. For example, the estimate of facility \#30 would require 22 person-years for current employees and 480 person-years (40,000 workers $x 24$ person-hr/worker) to estimate the internal doses for all employees, current and terminated.

The respondents indicate that 15 calculate a dose equivalent to the critical organ. However, the annotations which accompanied these positive responses seem to indicate that doses are not calculated for all intakes. For example, one facility (\#8) implies that doses to the critical organ are estimated for significant intakes and another response (\#35) states that the dose estimates to the critical organ "can be provided for monitored workers." 
Nineteen respondents indicate that the dose equivalent to the critical organ is not recorded. Comments on the questionnaire indicate that raw data may be available from in vivo or in vitro bioassays, or that the radioactivity in an organ is estimated, but not the dose.

In some instances, the extent of data interpretation of bioassay data may have depended upon the apparent magnitude of the intake and the radionuclide involved. For example, facility \#9 describes this situation: Plutonium exposures are presently expressed only as body burdens in $\mathrm{nCi}$ and nCi-yrs. Uranium exposures are available as intake quantities, based on ICRP-30 and ICRP Lung Model Concepts. Internal exposures to americium, polonium and miscellaneous other isotopes are known only to the extent of the bioassay results. This seems to mean that the ability to estimate a dose from internai exposures maj depend upon the particuiar radionucicide as well as the magnitude of any intake. Other responses indicate that internal dosimetry is not applicable at the particular facility.

The internally deposited radionuclide whose dose is included in the whole-body penetrating dose category is tritium although a few facilities included other radionuclides such as $125,129,131_{I},{ }^{51} \mathrm{CR},{ }^{137} \mathrm{Cs},{ }^{60} \mathrm{Co}$, $22,24 \mathrm{Na},{ }^{169} \mathrm{Yb}$ and ${ }^{90} \mathrm{Sr}$. Most respondents indicate that the dose from the internally dëposited radionuclide is placed in a separate category and the doses are summed for reporting purposes. Only one facility seems to record all penetrating doses in one category; their category is labeled " $\gamma+$ neutron + tritium."

RECORDS

Sixteen respondents indicate that their recordkeeping system meets the recommendations of ANSI N13.6. Three indicate that their system does not, while 14 do not know.

Twenty-eight of the facilities will record the fact that their employees had received a radiation dose at a previous work location. Twenty-six routinely obtain the radiation dose history for new employees and 26 also incorporate the previous dose into their records. If a previous dose history is obtained, all facilities state that they can distinguish between doses received at the previous place of employment and the facility itself; although one facility reports that such a distinction is not easily made. 
There has been a change of contractors at 10 facilities; however, at all but two facilities the radiation dose records were transferred to the present contractor. At one of the two facilities the locations of the records are apparently known (the previous contractor companies were naalled) a) though it is not clear if the present contractor knows whose records are kept by the previous contractors. The second contractor states that the dose records reside with the current contractor but that the "location of many dose records predating (the) early 50's (is) uncertain."

The questionnaire also asked if records were kept of the dosimetry methods so that the facility could demonstrate how a given dose was calculated. Twenty.three facilties report that this type of information is available for internal dosimetry and 30 facilities have that type of information for externai sose. Severai of the responsents indicated, in a general way, what the dose interpretation methods were. Only one respondent, however, quoted a document number which may mean that previously used dose interpretation methods may have to be reconstructed from records which may consist of technical publications and internal memos. In cases where standard methods were modified for individual observation, the methods o employed may be described in the individual workers dose file. The responses imply that it may be difficult to describe the exact method employed to estimate a radiation dose especially from internally deposited radionuclides.

\section{RADIATION RECORD COMPONENTS}

The radiation record components for which information was listed is shown in the appendix. Two major conclusions can be drawn from the responses. First, there is a marked difference between records for current workers and historic records; the current records are much more complete. Second, more facilities have records on external whole body dosimetry than on extremity or internal doses. This may be because several of the facilities claim to have had no or few exposures due to internally deposited radionuclides.

All facilities record the gamma exposure and 24 record neutron doses 10 of which apparently do not distinguish between fast and thermal neutrons. 
Twenty-four of the facilities record radionuclide excretion data and 15 flag their records to indicate that an intake has occurred. Twenty-one facilities record the identify of the radionuclide providing the dose. The date of radionuclide intake is recorded by 16 facilities and 12 will flag the date if it is an assumed date. Seventeen of the facilities record the activity in the critical organ and eight will record the activity in organs other than the critical organ, eleven facilities also estimate the activity in the whole-body. The annual dose to the critical organ is estimated at 13 facilities. The annual dose to organs in addition to the critical organ while 10 facilities record the annual or effective dose equivalent.

\section{GENERAL}

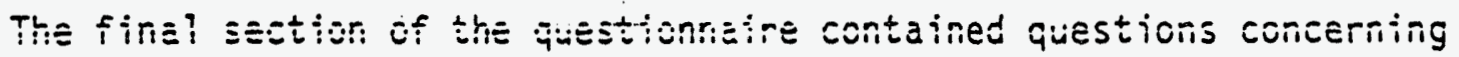
the filing system used and whether a computer was used to assist in recordkeeping. Of the 36 respondents, twenty-three indicate that computers are used to assist in maintaining radiation dose records. Of those who use a computer, 18 have developed their own software for file maintenance. Nine facilities indicate that a commercial data base management system is used to assist in record maintenance. Those that do use commercial systems seem to use heirarchical data base systems predominantly. Three facilities use the same commercial data base system.

Some of those facilities who do have computer systems do not have all of their records in the system. Other facilities have only external radiation doses on their systems.

\section{SUMMARY}

Estimation of annual radiation doses for all DOE/DOE contractor employees current and terminated could be an expensive process. The costs vary tremendously from facility to facility. Much of the variation is due to two items: First, the number of individuals who do or have worked at the facility. Second, the extent to which computers are used to manage the record system. Not all facilities utilize computers and facilities who do use computers do not have all of their records in their system. The respondents state that 
estimation of internal radiation doses may be impossible or very difficult at some facilities even though data from bioassays may be present.

The cost estimates to obtain the internal or external radiation doses may be slightly inflated for the following reason. The costs in some instances are based on the combination of cost to obtain one dose history and the total number of individuals for whom dose history may be required. If dose histories for all workers were required, it would be reasonable to enter all dose information into a computer which could then sort out the information. In the case of internal dose histories, the same procedures could be followed in order to identify those individuals who did not (have) a measurable internal exposures. A previous report (Traub et al.) indicated that only about $10 \%$ of workers at DOE facilities who participate in interna dosimetry programs have an interna: exposure due to greater than $10 \%$ of the maximum permissible internal exposures (as defined in DOE Order 5484.1, Chapter XI).

If the dose histories at the DOE facilities are collected manually, without the aid of computers, the costs may be reasonable estimates. If the records can be entered into computer systems which can sort the data then the costs should be less than the estimates of this report.

In order to determine the costs to place the radiation records in a computer system, one large facility (\#7) which apparently has all dosimetry records in a computer system was contacted by telephone. This facility has approximately 92,000 people on the system and the cost to do this was stated to be about $\$ 450,000$ : not all bioassay data is in the system however the costs to finish the work should not cause the total costs to be more than double the total expenditures to date.

The radiation dose records for DOE/DOE contractor employees should be incorporated into computer files. Facilities whose records are in computer files appear to be able to provide cumulative and annual dose estimates for individuals within short times and at reasonable costs. The costs of implementing computer systems at all facilities may be high but these costs may be less than the costs of attempting to extract information from a manual system. An additional benefit of computer based records is that placing 
exposure records in computer files forces those in charge of records to resolve apparent discrepancies in the records, such discrepancies might include name changes, double entry of data, missing data etc.

The descriptions of the recordkeeping system in Section $E$ and the radiation record components itemized in Section $D$ indicate that virtually all DOE/DOE contractor facilities have different and (probably) incompatable recordkeeping systems. Guidelines for recordkeeping systems should be established in assisting in the transfer of exposure histories in the event that workers transfer from one facility to another. 


\section{QUESTIONNAIRE ON RADIATION RECORDKEEPING SYSTEMS AT DOE/DOE CONTRACTOR FACILITIES}

$\because$ 


\section{INTRODUCTION}

This questionnaire relates to recordkeeping systems at DOE/DOE contractor facilities. The records of interest are those of lifetime radiation exposures (doses) to workers. The major question to be answered by this questionnaire is: Do you have the data to provide an accumulative lifetime radiation dose for every worker at your facility for both internal and external exposures, and if so, how much effort will be required to provide those estimates. A secondary but very important question is, if you do not have the data, what data are missing?

The impetus for this is to determine the impact of various schemes to compensate radiation workers who develop cancer. These schemes are based on attributable risk tables which purport to state the probability that a given cancer was caused by radiation. The attributable risk tables are broken down by organ, sex, age at exposure, dose received, and latency period. In order to judge the impact of these attributable risk tables, it is necessary that DOE/DOE contractor facilities be able to analyze the radiation doses received by workers in the same categories as contained in the tables.

This questionnaire should be filled out by the facility which has responsibility for keeping radiation exposure records. Please be as complete as possible in that the purpose of this questionnaire is, in part, to determine the ability of current systems to provide the requested data and the costs necessary to upgrade the current systems. If your radiation worker records system has been documented in any form or described either in internal documents or publications, please provide copies of those documents.

In order to prevent double counting of records systems, this questionnaire should be completed only by those DOE/DOE contractor facilities which are responsible for records.

Questions of a technical nature should be directed to Richard J. Traub on FTS (509) 375-6851. 
Please provide the following information in the event that additional information is necessary:

Name of individual completing

the questionnaire

Title

Department

DOE/DOE Contractor Organization

Site or Facility

Address

Telephone Number

If the resuits of this study are publisned, wouid you like a copy? Yes

No

In the event that additional follow-up questions may be necessary, who can be contacted by telephone?

Name

Address

Telephone Number

Note that when the results of this survey are surmarized, the sites will remain anonymous. Please list the DOE/DOE contractor facilities for which you maintain records. 
A. LIFETIME DOSES, EXTERNAL DOSES

The purpose of this section is to learn the availability of lifetime dose records at DOE/DOE contractor facilities for all individuals who are working, or have worked, at the facility. This availability refers to doses received while working at the particular facility.

1. Can your facility provide the lifetime cumulative external radiation dose received at your facility for all your currently employed workers, by individual (i.e., are the data available)?

$$
\text { Yes (also see questions } A 2, A 3 \text {, and } A 4 \text { ) }
$$

No (also see questions $A 3, A 5$ and $A 6$ )

2. Can you facility provide the lifetime cumulative external radiation dose received at your facility for all workers who have been employed at your facility (to date of termination)?

Yes (also see questions $A 3$ and $A 4$ )

No (also see questions $A 5$ and $A 6$ )

3. If $A 1$ or $A 2$ are Yes, what level of effort would be required to obtain this information? If costs are predominately computer costs, please indicate this fact and provide an estimate of cost. If costs are predominantely due to staff labor, please indicate the estimated man-hours to complete.

For current workers

For all workers

4. If $A 1$ or $A 2$ are Yes, within what period of time could you provide this information (e.g., 2 weeks, etc.)?

With Current Staffing Levels

With Additional

Staff (state additional staff required)

For current workers

For all workers 
5. If $A 1$ or $A 2$ are No, please explain why this would not be possible, i.e., what data are missing? Please be specific.

Current workers

All workers

6. If the data requested in $A 1$ or $A 2$ can be provided for some workers but not for others, please explain the reasons for the differences and provide data similar to A3, A4, and A5 for each category. 


\section{B. LIFETIME DATA, INTERNAL EXPOSURES}

The purpose of this section is to determine whether sufficient data exist to estimate the cumulative exposures to body organs from internal exposures. The interest is whether the facility can provide estimates of dose equivalent. This requirement is over and above knowledge of excretion rates or radioactive content of the body.

1. Can your facility provide the lifetime or annual internal radiation exposure data for all your currently employed workers, by individual (i.e., are the data available)?

$$
\text { Yes (also see questions B2, B3, B4, B5, B7 and following) }
$$

No (also see questions B2, B6 and following)

2. Can you facility provide the lifetime cumulative internal radiation exposure for all workers who have been employed at your facility (to date of ierminationj?

Yes (also see questions B3, B4, B5, B7 and following) No (also see questions $B 6$ and following)

3. If the above answer is yes, what data are recorded?

3 Integrated air concentrations

23 Bioassay results (urine or fecal analysis)

19 Whole body count results

6 Evaluation of mathematical models to estimate deposition

10 Calculated internal dose

Other (please explain) Annual Bioassay, Various Reports and Incident Files

4. If Yes, what level of effort would be required to obtain this information? If costs are predominately computer costs, please indicate this fact and provide an estimate of cost. If costs are predominantely due to staff labor, please indicate the estimate man-hours to complete. 
For current workers

For all workers

5. If $B 1$ or $B 2$ are Yes, within what period of time could you provide this information (e.g., 2 weeks, etc.)?

With Current

Staffing Levels

With Additional

Staff (state additional staff required)

For current workers

For a 11 workers

6. If $B 1$ or $B 2$ are No, please explain why this would not be possible. Please be specific. For example, internal doses are not recorded, internal doses are not readily computed from existing data.

Current workers

Al1 workers

7. Do you calculate a dose equivalent to the critical organ from internally deposited radionuclides?

\section{Yes}

No

8. If you do not calculate radiation dose equivalents from internally deposited radionuclides, please describe what data you record concerning internal exposures and the types of analyses which may be possible to perform on the data (e.g., record urine excretion data only, record excretion data and in vitro whole body/organ count data and estimated organ burdens, etc.). 
9. If the data requested in B1 or B2 can be provided for some workers but not for others, please explain the reasons for the differences and provide data similar to B3, B4, and B5 for each category.

10. If there are exposures to short-lived emitters, such as ${ }^{24} \mathrm{Na},{ }^{125} \mathrm{I}$, I, how is this data recorded and how is the dose integrated into an annual dose? which the whole body is the critical organ, e.g., ${ }^{3}$, into the whole body penetrating dose category?

Yes

No

12. If the answer to question $B 9$ is Yes, how do you indicate that such an addition has been made (e.g., do you have a separate category for internal emitters)?

13. Which radionuclides do you include in the whole body penetrating dose category? 


\section{RECORDS}

1. Do your records satisfy the requirements of ANSI N13.6 (Practice for Occupational Radiation Exposure Records Systems)?

16 Yes

3 No

14 Do not know

2. If an employee has received a radiation dose while working for a previous employer,

a. is the fact of this previous dose recorded (i.e., flagged)?

28 Yes

$\ddot{8}$ No

b. do you routinely obtain the radiation dose history for new employees?

26 Yes

8 No

c. If a radiation dose history is obtained;

is the dose history incorporated into your records?

26 Yes

7 No

can you distinguish between dose received at previous employer locations and your facility?

34 Yes

No

3. Has there ever been a change of contractors at your facility? $16 \mathrm{Y}, 24 \mathrm{~N}$

4. If there has been a change of contractors at your facility, where are the dosimetry records of previous contractors?

With previous contractor

With current contractor

Other (please specify) 
5. Do you maintain records which describe the dosimetry methods employed for external or internal radiation doses? That is, for each radiation dose recorded, can you document the procedures employed to estimate that dose?

Dose Interpretation Methods
a) Internal exposures 23 - Yes
6 No
b) External exposures 30 Yes
4 No 


\section{RADIATION RECORD COMPONENTS}

Please indicate which of the following are in your radiation dose records. If the records in previous years are not as detailed, please explain which components are missing from these historical records.

[n.b. numbers are total number of respondents who record the stated item] Current Historical Records Records

\begin{tabular}{lcc} 
& & 36 \\
a. Name & 36 & 29 \\
\hline b. Social Security Number & 36 & 19 \\
\hline c. Date of Birth & 34 & 22 \\
\hline d. Sex & 23 & 16 \\
\hline e. Termination date, if appropriate & 30 & 24 \\
\hline f. Date of death, if appropriate & 5 & 6 \\
\hline
\end{tabular}

Whole Body Component

\begin{tabular}{llcc}
\hline g. & gamma & 36 & 30 \\
\hline h. & neutron, fast & 25 & 17 \\
\hline$j . \quad$ neutron, thermal & 14 & 11 \\
\hline$j . \quad \begin{array}{l}\text { dose from interna radionuclides } \\
\text { where whole body is critical organ }\end{array}$ & 15 & 11 \\
\hline k. $\quad \begin{array}{l}\text { if } j, \text { are the records flagged to } \\
\text { indicate such an addition }\end{array}$ & 8 & $\frac{6}{23}$ \\
\hline.$\quad$ total whole body dose & 28 & 13 \\
\hline m. & offsite dose, if appropriate & 18 & 18 \\
\hline
\end{tabular}

Skin Component

$\frac{\text { n. beta }}{0 .}$ low energy photon

$\begin{array}{rr}29 & 22 \\ 17 & 6\end{array}$

Extremity

p. Teft upper

g. right upper

r. left lower

s. right lower

t. any extremity (which are not indicated)

Interna] Dose Component

u. flag that intake occurred

$v$. date of intake

w. flag if date of intake is assumed

X. radionuclide excretion data

$y$. activity in critical organ

z. activity in organs in addition to critical organ

aa. annual dose to critical organ

bb. annual dose to each organ listed in $x$

cc. activity in whole body

dd. annual/effective dose equivalent

ee. identity of radionuclides providing dose

\begin{tabular}{cc}
13 & 9 \\
\hline 13 & 11 \\
\hline 4 & 3 \\
\hline 4 & 3 \\
\hline 8 & 8
\end{tabular}




\section{E. GENERAL}

The purpose of these questions is to assist in determining the present state of recordkeeping systems. The data which these questions will provide will help to estimate costs to automate the records systems at DOE facilities. These costs will include not only the size of machines which may be required to process the data but also the time necessary to enter the exposure data into the computer on a continuing basis and, if necessary, all past exposure records.

1. What is the number of currently employed workers for which you have radiation dosimetry records? (Please list the numbers separately for each DOE/DOE contractor facility)

2. What is the total number of workers (current and terminated) for which you have records?

3. What is the average number of dose entries per worker per year?

4. Is all data for current employees maintained (check all that apply)?

- on site

government storage center other, (please describe)

5. Is all data for past (terminated) employees maintained (check all that apply),
onsite
government storage center other, (please describe) 
6. Do you use a computer to assist in managing radiation exposure records?

23 Yes (please answer question E7 below)

13 No

7. If the answer to question $E 6$ is Yes

a) When were the computer code(s) for the system developed? Code Name/Designator Date Developed (if known)

b) Was the system developed inhouse or was it a product of a commercial vendor?

18 in-house, 12 -vendor

If the system was a product of a commercial vendor, please state the product name and revision number.

c) If you were asked to provide information, as for example, the job category of workers receiving more than $2 \mathrm{rem} / \mathrm{year}$, what would be required, e.g., would you need to write a new program, simply access the data by a specified query language, etc.

d) If your system utilizes a data base management system: Who is the vendor?

What is the name of the system?

Which revision are you using? 
8. If your records are in different record storage forms depending upon certain characteristics, e.g., age of record, please explain,

Category Storage Form (a) No. of Workers/Records

1) e.g.

Ail currently

employed

Computer disk

2000 workers

present to 1979

Backup to above Original hard copy

(a) Examples of storage forms are: computer tape, computer disk, punched cards, microform, paper tape, hand written, typed, etc.

9: If your records system is a manual (not computer based) system, please describe the system. For example, we would like to know if all dosimetry records for a given year ie together, if you utilize an employee file in which all dosimetry data for a single individual are maintained in one file, etc. 

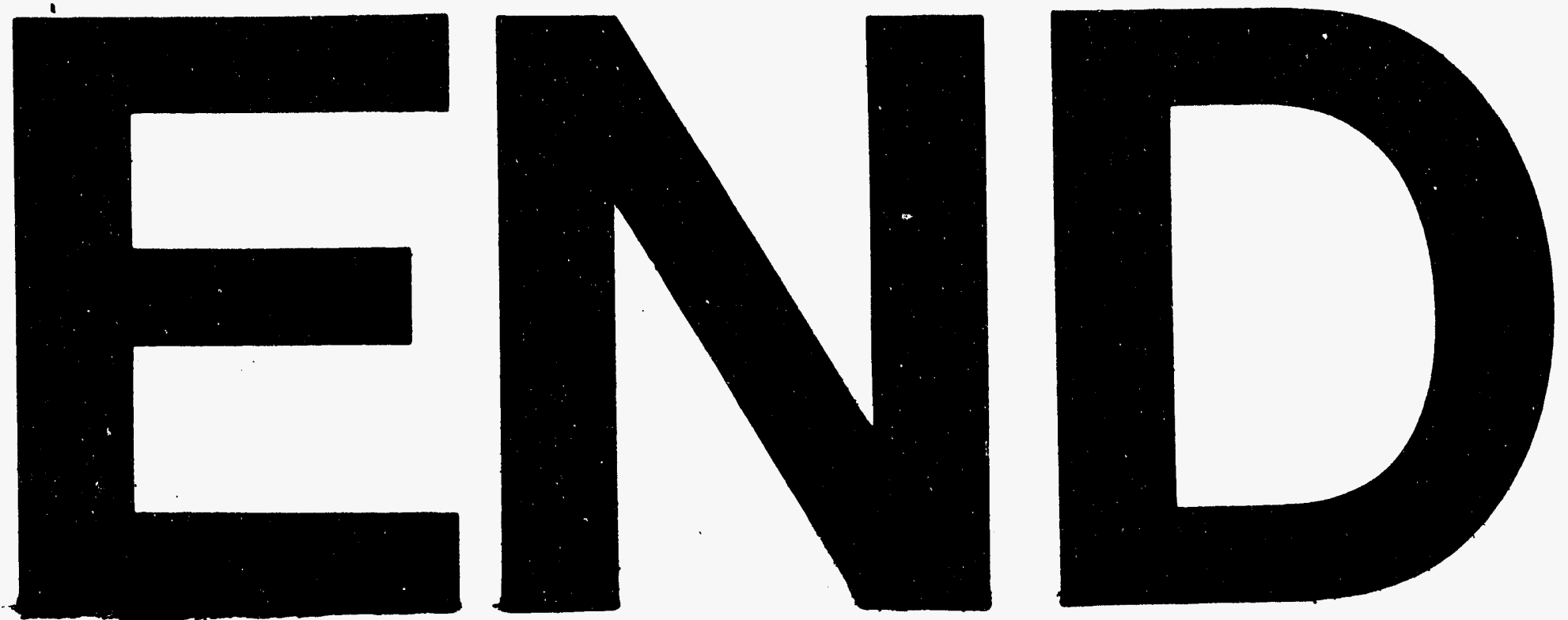

$\$$
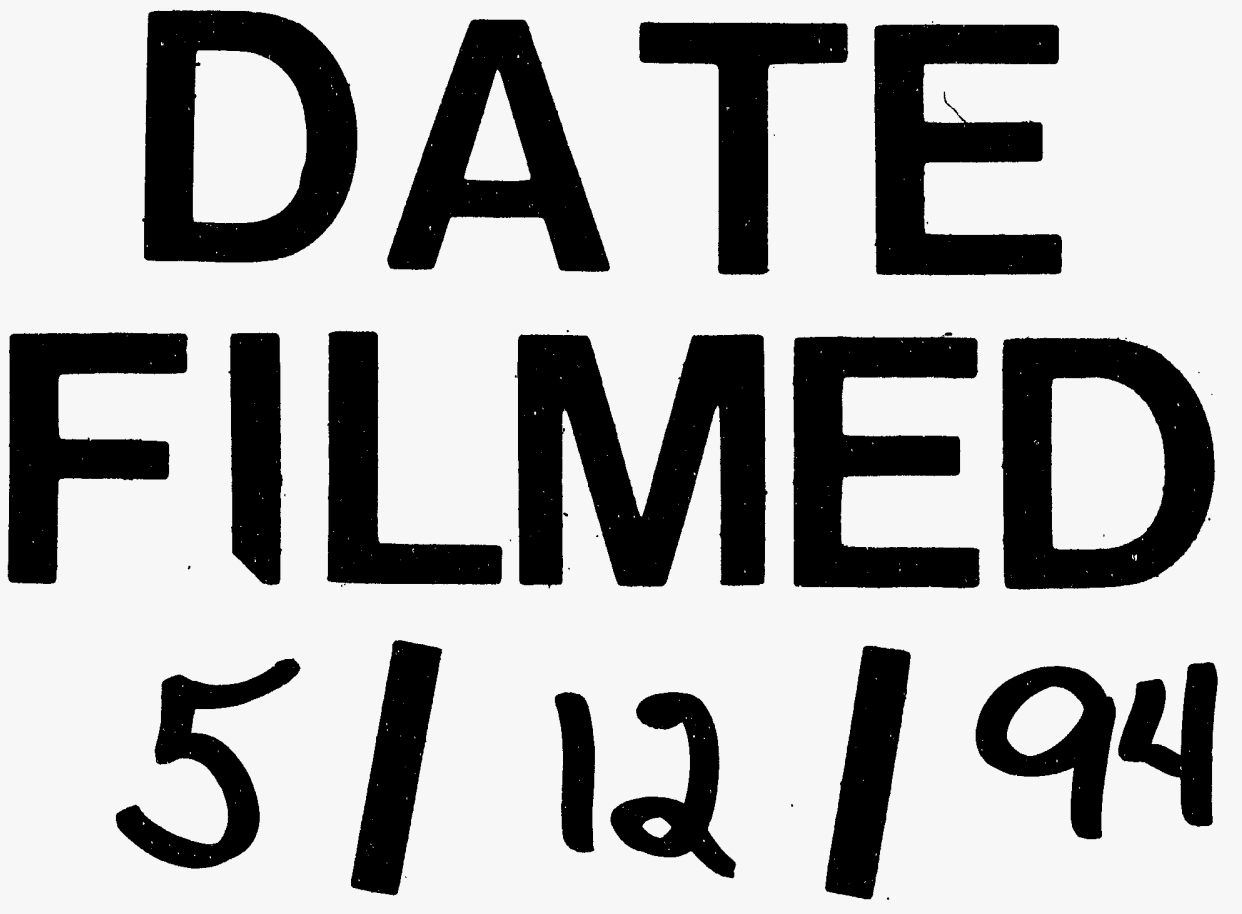
